\title{
Escola EsTadual DaURY RIVA: IDENTIDADE E HISTÓRIA - DE SALA ANEXA À ESCOLA PLENA
}

\author{
DAURY RIVA STATE SCHOOL: IDENTITY AND HISTORY - FROM ROOM \\ ADJACENT TO FULL SCHOOL
}

DOI: http://dx.doi.org/10.23926/RPD.2526-2149.2019.v4.n2.p810-822.id489

\author{
Valdenir \\ Schoenberger \\ Especialização em Educação \\ Física Escolar, Saúde e \\ Qualidade de Vida e Práticas \\ Contemporâneas pela Hórus \\ Faculdades \\ mano_schoenberger@hotmai \\ 1.com
}

\begin{abstract}
Resumo: Este ensaio tem como enfoque a construção de um documento para o resgate da identidade e conservação da memória histórica e cultural da Escola Estadual Daury Riva. O objeto aqui relatado caracteriza-se na salvaguarda da identidade e da história envolvida no desenvolvimento e criação da escola no Município de Juara/MT. A seleção e leitura dos documentos basilares e consulta bibliográfica permitiram construir em parte a história da unidade. A escola inicia suas atividades no ano de 2010, mas logo nos primeiros anos de funcionamento sente um decréscimo no quadro de alunos, sendo assim inicia-se no ano de 2014 o Programa Mais Educação, com o objetivo de aumentar a jornada escolar. Com o fim do Programa Mais Educação, a escola adere em 2016 o Projeto Educação Integral em Tempo Integral, culminando no atual Projeto Escola Plena que teve início no ano de 2019. A escola atende cerca de (200) duzentos alunos dos dois segmentos de ensino da Educação Básica (Ensino Fundamental - Anos Iniciais e Anos Finais) que estudam em período integral contemplando a Base Curricular Comum, Base Diversificada e Disciplinas Eletivas, os quais têm a oportunidade de participar de práticas que incorporam sentido e significado nos seus estudos.
\end{abstract}

Palavras-chave: Educação; Educação Integral; Escola Plena.

\begin{abstract}
This essay focuses on the construction of a document for the recovery of the identity and conservation of the historical and cultural memory of Daury Riva State School. The object reported here is characterized in safeguarding the identity and history involved in the development and creation of the school in the city of Juara / MT. The selection and reading of the basic documents and bibliographic consultation allowed to build in part the history of the unit. The school starts its activities in 2010, but already in the first years of operation it feels a decrease in the number of students, thus starting in 2014 the More Education Program, with the objective of increasing the school day. With the end of the More Education Program, the school joins the Full-Time Integral Education Project in 2016, culminating in the current Full School Project that began in 2019. The school serves about (200) two hundred students from both education segments. Elementary School (Elementary School - Early Years and Final Years) students who study full time with Common Curricular Basis, Diversified Basis and Elective Disciplines, who have the opportunity to participate in practices that incorporate meaning and meaning in their studies.
\end{abstract}

Keywords: Education; Integral Education; Full School. 


\section{INTRODUÇÃO}

Sendo uma das (07) sete Escolas Estaduais Urbanas do Município de Juara, localizada na Avenida Paraná, no 750 “E”, Bairro Residencial Santa Teresinha, próximo ao Bairro Jardim Eldorado, saída para a Comunidade do Jaú, região que até o ano de 2006 se estabelecia como área de Zona Rural pertencente ao Município (PPP1, 2015). A Escola Estadual Daury Riva, instituição sem fins lucrativos, á qual tem como patrono o Senhor Daury Riva, o qual nasceu em 14/11/1935, na Cidade de Alegre/ES, e veio a falecer no dia 16/01/2008. Casado com a Senhora Maria Pirovani Riva, com quem teve seis filhos, Daury Riva foi um dos pioneiros e chegou à cidade de Juara no final da década de 70, onde sempre desenvolveu atividades relacionadas à agropecuária, contribuindo desta forma com o crescimento e desenvolvimento da região (PPP, 2018).

O surgimento do tramite que resultou na criação da Instituição de Ensino Daury Riva se deu no ano de 2010, quando as demais unidades escolares do Munícipio de Juara passaram por um processo delicado com relação a excedente demanda de matrículas para alunos da rede pública e particular de ensino. Uma vez que houve a desativação de duas escolas na cidade (Núcleo Educacional Delta e Escola Agrícola Municipal Artur Pinoti), fazendo com que o excedente de alunos procurasse vagas para estudar na rede pública estadual de ensino. Outro fator decisivo foi que a Escola Estadual Iara Maria Minotto, situada no Bairro Jardim América, a qual atende a clientela local, além dos bairros de Porto Seguro, Portal das Flores e outros com grande demanda de alunos, possuía excedente de aproximadamente (110) cento e dez alunos sem salas de aula para o ano letivo de 2010, uma vez que possuía apenas o ínfimo número de (12) doze salas de aula, as quais eram superlotadas e estava na ocasião, em processo de licitação para reforma e construção de novas salas (PPP, 2015).

Desta forma a Instituição Abençoe de Juara, a qual desenvolve suas funções basilares pautadas em um cunho filantrópico e social, em parceria com a Secretaria de Estado de Educação de Mato Grosso - SEDUC - MT, no intuito de sanear sobre a situação até aqui apresentada, alocou o prédio do Núcleo Educacional Delta (desativado em 2009), localizado na Rua José Martins, Centro, Juara/MT. A unidade era composta por (07) sete salas de alvenaria, (02) dois banheiros para alunos, (01) banheiro para funcionários, (01) cozinha com depósito de merenda, (01) sala de professores, (01) refeitório, (01) sala de coordenação, (01) sala de direção, (01) área de serviço e (01) secretaria para atender á crescente demanda no número excedente

\footnotetext{
${ }^{1}$ PPP - Projeto Político Pedagógico.
} 
de alunos do município, os quais (285) duzentos e oitenta e cinco alunos foram lotados de forma temporária, e pertencentes como sala anexa da Escola Estadual Iara Minotto Gomes, até meados de março de 2010, suprindo a necessidade de vagas para o Município, e assim iniciando os trabalhos educacionais em um ambiente que não era muito propício para tais atividades (PPP, 2015).

\begin{abstract}
Iniciando os trâmites de legalização do anexo observou-se que de acordo com a resolução no 157/02 do CEE/MT que regulamenta o Regime de oferta de Educação Básica em salas anexas para as Escolas Públicas em seu artigo $2^{\circ}$ e $\S 3^{\circ}$ o qual dispõem que [...] comprovada à demanda superior de (120) cento e vinte alunos, cabe-se a criação de uma unidade escolar, não foi possível regulamentar o anexo e sim a necessidade de se criar uma nova escola, desta forma e diante da realidade do número de alunos a sociedade local concordou com a criação de uma nova unidade escolar para o município, suprindo assim o anexo escolar e criando a Escola Estadual Daury Riva, mantida pela SEDUC-MT, a qual foi desmembrada da Escola Estadual Iara Minotto Gomes, em 26 de março de 2010, pelo decreto 2.647 pág. 02 do Diário Oficial de mesma data, e ficou locada no prédio do antigo Colégio Delta, até que finalização da construção da sede própria (Prédio escolar que possui o modelo Escola Atrativa com dois pisos e 12 salas de aula, no Bairro Residencial Santa Terezinha), o qual ocorreu em dezembro de 2011 (PPP, 2015, p. 04).
\end{abstract}

A Escola Estadual Daury Riva conta com espaço físico escolar privilegiado pela dimensão do terreno onde a mesma está localizada, o qual possui 18.306,46 m2 de área mudara, cujo interior possui o prédio desenvolvido e construído dentro das concepções do Programa com modelo de Escola Atrativa: ambiente amplo, arejado e agradável. Estruturada em dois pisos com (12) salas de aula, (01) banheiro para funcionários, (01) biblioteca com acervo de cerca de (3.000) três mil livros - infantis, infanto-juvenil, enciclopédias e dicionários, (01) laboratório de informática com (18) dezoito computadores - sistema operacional Linux, (01) cantina, (01) quadra poliesportiva, (01) quadra de areia, (04) banheiros para alunos, (01) cozinha com depósito de merenda, (01) sala de professores, (01) refeitório, (02) vestiários, (01) sala de coordenação, (01) sala de direção, (01) área de serviço e (01) secretaria (PPP, 2015).

O Projeto Pedagógico de Educação em Tempo Integral (2019, p. 06) tem como objetivo: "[...] planejar, executar e avaliar um conjunto de ações inovadoras em conteúdo, método e gestão, direcionadas à melhoria da oferta e da qualidade da educação na rede pública do Estado”. Desta forma o documento está fundamentado na Constituição de 1988, que preconiza a Educação como um direito fundamental; na Lei de Diretrizes e Bases da Educação Nacional 9394/96 (art. 34) prevê a ampliação gradativa da jornada escolar com o objetivo de democratizar as oportunidades de aprendizagem e no Plano Nacional de Educação (2014, p. 97) que na sua Meta (6) seis pretende: “oferecer educação em tempo integral em, no mínimo, 50\% 
(cinquenta por cento) das escolas públicas, de forma a atender, pelo menos, 25\% (vinte e cinco por cento) dos (as) alunos (as) da educação básica".

Ao longo dos (10) dez anos de funcionamento a Escola Estadual Daury Riva teve que se reinventar frente às politicas educacionais superficiais implantadas de forma abrupta e sem respaldo de acompanhamento dos órgãos competentes. Segue-se a seguir a descrição dos Projetos Educacionais implantados ao longo de quase uma década de funcionamento institucional.

\section{Projeto Mais EducaÇÃo}

No decorrer de poucos anos, a Escola Estadual Daury Riva começou a sofrer com a baixa demanda de alunos, e um dos motivos foi devido sua localização encontrar-se distante do centro da cidade, houve então uma mobilização por parte do corpo docente e da comunidade em geral, na busca de novas alternativas para a continuidade das atividades escolares, então em 2014 tem início o Projeto Mais Educação (PPP, 2018). O Programa Mais Educação foi instituído pela Portaria Interministerial n ${ }^{\circ}$ 17/2007 e pelo Decreto $n^{\circ} 7.083$, de 27 de janeiro de 2010, cuja função tem um cunho integrador nas ações do Plano de Desenvolvimento da Educação (PDE), e como uma estratégia do Governo Federal para a ampliação da jornada escolar e a organização curricular, na perspectiva da Educação Integral (BRASIL, 2014). Ainda segundo (BRASIL, 2014, p. 04):

Trata-se da construção de uma ação Inter-setorial entre as políticas públicas educacionais e sociais, contribuindo, desse modo, tanto para a diminuição das desigualdades educacionais, quanto para a valorização da diversidade cultural brasileira. Essa estratégia promove a ampliação de tempos, espaços, oportunidades educativas e o compartilhamento da tarefa de educar entre os profissionais da educação e de outras áreas, as famílias e diferentes atores sociais, sob a coordenação da escola e dos professores.

O Projeto Mais Educação era desenvolvido no contra turno ao qual o aluno estava devidamente matriculado, e o qual, poderia desenvolver as seguintes modalidades (BRASIL, 2014, p. 05-07):

A) Acompanhamento pedagógico (Orientação de Estudos e Leitura);

B) Comunicação, uso de mídias e cultura digital e tecnológica (Ambiente de Redes Sociais, Fotografia, Histórias em Quadrinhos, Jornal Escolar, Rádio Escolar, Vídeo, Robótica Educacional e Tecnologias Educacionais);

C) Cultura artes e educação patrimonial (Artesanato Popular, Banda, Canto Coral, Capoeira, Cineclube, Danças, Desenho, Educação Patrimonial, Escultura/Cerâmica, Grafite, Hip-Hop, Iniciação Musical de Instrumentos de Cordas, Iniciação Musical por meio da Flauta Doce, Leitura e Produção Textual, Leitura: Organização de Clubes de Leitura, Mosaico, Percussão, Pintura, Práticas Circenses, Sala Temática para o Estudo de Línguas Estrangeiras, Teatro); 
D) Educação ambiental, desenvolvimento sustentável e economia solidária e criativa/educação - educação financeira e fiscal (Horta Escolar e/ou Comunitária, Jardinagem Escolar, Economia Solidária e Criativa /Educação Econômica Educação Financeira e Fiscal);

E) Esporte e lazer (Atletismo, Badminton, Basquete de Rua, Basquete, Corrida de Orientação, Esporte da Escola/Atletismo e Múltiplas Vivências Esportivas (basquete, futebol, futsal, handebol, voleibol e xadrez), Futebol, Futsal, Ginástica Rítmica, Handebol, Judô, Karatê, Luta Olímpica, Natação, Recreação e Lazer/Brinquedoteca, Tae-kwon-do, Tênis de Campo, Tênis de Mesa, Voleibol, Vôlei de Praia, Xadrez Tradicional, Xadrez Virtual e Yoga/Meditação);

F) Educação em direitos humanos (Educação em Direitos Humanos);

G) Promoção da saúde (Promoção da Saúde e Prevenção de Doenças e Agravos à Saúde).

Infelizmente o Projeto Mais Educação durou pouco, iniciou-se em 2014 e encerrou suas atividades em meados de 2015, frente às dificuldades orçamentarias apresentadas.

Embora o Projeto mais Educação tenha oportunizado um aumento na carga horária dentro do âmbito escolar, em muito deixou a desejar. Visto que a prioridade do Governo Federal foi designar ínfimos recursos para as unidades escolares sem ao menos estabelecer critérios ou oportunizar uma rede de apoio com o intuito de averiguar a viabilidade e aplicabilidade das atividades realizadas no projeto, como bem salientam (Silva e Silva, 2013, p. 706): “É importante destacar ainda o fato de o governo federal se colocar apenas na posição de indutor, não garantindo as condições objetivas essenciais ao pleno desenvolvimento da política de educação integral”. Ainda segundo os autores (2013, p. 715):

Em relação aos fins do projeto político-pedagógico, constatamos que a equação proteger e educar, que é uma das justificativas para a ampliação da jornada escolar, em vez de superar as experiências passadas, renovam e aprofundam a ideia de educação compensatória, robustecendo a escola com uma série de tarefas não propriamente educativas, que só podem gerar sobrecarga e intensificação do trabalho dos educadores e encurtar a sua função de socialização do conhecimento historicamente acumulado. Isso porque a ampliação da jornada escolar não vem acompanhada da garantia das condições de trabalho adequadas, sendo a maior parte das responsabilidades repassada aos estados e municípios que são, em sua grande maioria, detentores de parcos orçamentos.

Desta forma a Escola Estadual Daury Riva volta suas atividades educacionais única e exclusivamente como Educação Básica Regular em dois turnos (Matutino e vespertino).

\section{Projeto EducaÇÃo InTEgral EM TEMPo INTEGRAL}

Para o início do ano letivo de 2016 a Escola Estadual Daury Riva foi contemplada com o Projeto de Educação Integral em Tempo Integral. No mês de janeiro de 2016, por intermédio da Portaria Nº. 035/2016/GS/SEDUC/MT no Diário Oficial de 26 de janeiro de 2016, e da Portaria No 037/2016/GS/SEDUC/MT de 28 de janeiro de 2016, a SEDUC inaugura o projeto referência com a implantação de (06) seis escolas em tempo integral, sendo (2) no Município 
de Cuiabá (Escola Estadual Antônio Epaminondas e Escola Estadual José de Mesquita); (02) no Município de Rondonópolis (Escola Estadual Pindorama e Escola Estadual André Antônio Maggi); (01) no Município de Juara (Escola Estadual Daury Riva) e (01) no Município de Arenápolis (Escola Estadual Alfredo de Araújo Granja).

A nova proposta curricular vem ao encontro com a necessidade institucional e tem seu fortalecimento embasado no PEE - Plano Estadual de Educação, Lei nº 10.111 de 06 de junho de 2014, e no PNE - Plano Nacional de Educação, Lei n ${ }^{\circ} 13.005$ de 25 de junho de 2014.

Promover, com apoio da União, a oferta de educação básica pública em tempo integral, por meio de atividades de acompanhamento pedagógico e multidisciplinares inclusive culturais e esportivas, de forma que o tempo de permanência dos alunos na escola, ou sob responsabilidade, passe a ser igual ou superior a sete horas diárias durante todo o ano letivo, com a ampliação progressiva da jornada de professores em uma única escola (BRASIL, 2014, p. 98).

Meta 16 - Aumentar progressivamente a carga horária em 01 hora por ano, atingindo pelo menos sete horas diárias, para $25 \%$ (vinte e cinco por cento) dos estudantes matriculados na educação básica até 2017 (MATO GROSSO, 2014, p. 39).

A concepção do currículo assumida no Ensino Fundamental: atende os (03) três ciclos de Formação Humana com duração de (09) nove anos - Anos Iniciais e Anos Finais - adotada o regime anual, respeitando o período de (200) duzentos dias letivos em que se realizam as aulas e demais atividades escolares com carga horária mínima de (800) oitocentas horas - Base Nacional Comum, juntamente com mais (600h) seiscentas horas - Parte Diversificada, conforme a legislação.

Baseado nas Orientações Curriculares do Estado de Mato Grosso (2010), nos Parâmetros Curriculares Nacionais (1997) e na Lei de Diretrizes e Bases da Educação Nacional (1996), o currículo escolar vem como uma base na formação humana trabalhada em todas as áreas do conhecimento, vinculando à prática diária a realidade mais próxima de nossos alunos. O Ensino Fundamental Regular desenvolve sua matriz curricular oportunizando as seguintes disciplinas obrigatórias: Matemática (04 horas semanais), Língua Portuguesa (04 horas semanais), Língua Inglesa (02 horas semanais), Educação Física (02 horas semanais), Geografia (02 horas semanais), História (03 horas semanais), Ciências (02 horas semanais), Arte (01 hora semanal), além dos trabalhos de Unidocência da $1^{\mathrm{a}}$ Fase do $1^{\circ}$ Ciclo até a $2^{\mathrm{a}}$ Fase do $2^{\circ}$ Ciclo (PPP, 2015).

Quadro 1 - Matriz Curricular: Base Nacional Comum

\begin{tabular}{|l|c|c|c|c|c|}
\hline \multicolumn{2}{|c|}{ Escola Estadual Daury Riva } & $6^{\circ}$ Ano & $7^{\circ}$ Ano & $8^{\circ}$ Ano & $9^{\circ}$ Ano \\
\hline \multirow{2}{*}{ Linguagem } & Língua Portuguesa & $04 \mathrm{~h}$ & $04 \mathrm{~h}$ & $04 \mathrm{~h}$ & $04 \mathrm{~h}$ \\
\cline { 2 - 7 } & Educação Física & $02 \mathrm{~h}$ & $02 \mathrm{~h}$ & $02 \mathrm{~h}$ & $02 \mathrm{~h}$ \\
\hline
\end{tabular}




\begin{tabular}{|c|c|c|c|c|c|}
\hline & Arte & $02 \mathrm{~h}$ & $02 \mathrm{~h}$ & $02 \mathrm{~h}$ & $02 \mathrm{~h}$ \\
\cline { 2 - 6 } & Língua Inglesa & $02 \mathrm{~h}$ & $02 \mathrm{~h}$ & $02 \mathrm{~h}$ & $02 \mathrm{~h}$ \\
\hline \multirow{2}{*}{ Matemática } & Matemática & $04 \mathrm{~h}$ & $04 \mathrm{~h}$ & $04 \mathrm{~h}$ & $04 \mathrm{~h}$ \\
\hline Ciências da natureza & Ciências & $02 \mathrm{~h}$ & $02 \mathrm{~h}$ & $02 \mathrm{~h}$ & $02 \mathrm{~h}$ \\
\hline \multirow{2}{*}{ Ciências Humanas } & História & $02 \mathrm{~h}$ & $02 \mathrm{~h}$ & $02 \mathrm{~h}$ & $02 \mathrm{~h}$ \\
\cline { 2 - 6 } & Geografia & $02 \mathrm{~h}$ & $02 \mathrm{~h}$ & $02 \mathrm{~h}$ & $02 \mathrm{~h}$ \\
\hline \multicolumn{4}{|c|}{ Total de horas } & $20 \mathrm{~h}$ \\
\hline
\end{tabular}

Fonte: PPP (2018).

Além das disciplinas acima citadas a escola oferece uma Base Diversificada de componentes curriculares (macro-campos) os quais se fundamentam em uma Educação Integral em Tempo Integral, um projeto curricular complementar de (15) quinze horas semanais desenvolvidos no período vespertino.

Quadro 2 - Matriz Curricular: Base Diversificada

\begin{tabular}{|c|c|c|}
\hline \multicolumn{3}{|c|}{ Escola Estadual Daury Riva } \\
\hline \multicolumn{3}{|c|}{$1^{\circ}$ ao $3^{\circ}$ ano } \\
\hline Macrocampo I & Atividades de convivência hábitos higiênicos e alimentares & $01 \mathrm{~h}$ \\
\hline Macrocampo II & Atividades de linguagem e matemática & $03 \mathrm{~h}$ \\
\hline Macrocampo III & Atividades culturais e artísticas & $03 \mathrm{~h}$ \\
\hline Macrocampo IV & Atividades esportivas e motoras & $03 \mathrm{~h}$ \\
\hline Macrocampo V & Atividades de formação pessoal e social & $03 \mathrm{~h}$ \\
\hline Macrocampo VI & Atividades de mídias digitais e tecnológicas & $02 \mathrm{~h}$ \\
\hline \multicolumn{2}{|c|}{$4^{\circ}$ ao $5^{\circ}$ ano } & $15 \mathrm{~h}$ \\
\hline Total de horas & $01 \mathrm{~h}$ \\
\hline Macrocampo I & Atividades de convivência hábitos higiênicos e alimentares & $03 \mathrm{~h}$ \\
\hline Macrocampo II & Atividades de linguagem e matemática & $03 \mathrm{~h}$ \\
\hline Macrocampo III & Atividades culturais e artísticas & $03 \mathrm{~h}$ \\
\hline Macrocampo IV & Atividades esportivas e motoras & $03 \mathrm{~h}$ \\
\hline Macrocampo V & Atividades de formação pessoal e social & $02 \mathrm{~h}$ \\
\hline Macrocampo VI & Atividades de mídias digitais e tecnológicas & $15 \mathrm{~h}$ \\
\hline Macrocampo I & Atividades de convivência hábitos higiênicos e alimentares & $01 \mathrm{~h}$ ano \\
\hline
\end{tabular}




\begin{tabular}{|c|c|c|}
\hline Macrocampo II & Atividades de linguagem e matemática & $03 \mathrm{~h}$ \\
\hline Macrocampo III & Atividades culturais e artísticas & $03 \mathrm{~h}$ \\
\hline Macrocampo IV & Atividades esportivas e motoras & $03 \mathrm{~h}$ \\
\hline Macrocampo V & Atividades de formação pessoal e social & $03 \mathrm{~h}$ \\
\hline Macrocampo VI & Atividades de mídias digitais e tecnológicas & $02 \mathrm{~h}$ \\
\hline \multicolumn{2}{|c|}{ Total de horas } & $15 \mathrm{~h}$ \\
\hline
\end{tabular}

Fonte: PPP (2018).

Desta forma, objetiva-se o desenvolvimento do ser em sua integralidade, ou como salienta (Gonçalves 2006, p. 3):

Educação integral é aquele que considera o sujeito em sua condição multidimensional, não apenas na dimensão cognitiva, como também na compreensão de um sujeito que é sujeito corpóreo, tem afetos e está inserido num contexto de relações. Isto vale dizer a compreensão de um sujeito que deve ser considerado em sua dimensão biopsicossocial.

\section{Projeto Escola Plena}

A Portaria $N^{\circ}$ 602/2018/GS/SEDUC/MT, de 26 de outubro de 2018 vem para implementar o Projeto Escola Plena em 40 Escolas do Estado de Mato Grosso. Na verdade o Projeto Escola Plena já uma era realidade, mas, ele era garantido unicamente na aplicação da Educação Plena no Ensino Médio, estabelecida pela Lei № 10.622, de 24 de outubro de 2017 que estabelece o Projeto Escola Plena, vinculado ao Programa Pró-Escolas, que consiste no funcionamento em tempo integral de escolas estaduais de ensino médio.

Como a Escola Estadual Daury Riva já estava em funcionamento com o formato do já mencionado Educação Integral em Tempo Integral, ocorre novamente uma mudança em seu quadro institucional, desta vez para o formato de Escola Plena. Sendo uma das 40 escolas em tempo integral no Estado, seu objetivo está voltado para dar condições aos estudantes matogrossenses para o desenvolvimento pleno de seus projetos de vida.

Com o intuito de empreender na formação integral dos discentes, a Escola Plena desenvolve paralelamente a Base Nacional Comum uma Base Diversificada do currículo. Oferecendo aulas interdisciplinares, a Base Diversificada estabelece uma relação de proximidade junto à Base Nacional Comum, servindo como mecanismo auxiliar e contemplativo no desenvolvimento das atividades escolares. Para Hora e Coelho (2004, p. 9):

[...] essas atividades constituem-se por práticas que incluem os conhecimentos gerais; a cultura; as artes; a saúde; os esportes e o trabalho. Contudo, para que se complete essa formação de modo crítico-emancipador, é necessário que essas práticas sejam trabalhadas em uma perspectiva político-filosófica igualmente crítica e emancipadora. 
Podemos ainda, apresentar as contribuições de (FODRA 2015, p. 05):

O diferencial está justamente na parte diversificada do currículo que oferece aulas e metodologias interdisciplinares criadas a partir das necessidades dos alunos, com o objetivo de estimular a construção e consolidação dos seus Projetos de Vida. Além da Base Nacional Comum, as escolas que participam do Programa têm na sua Matriz Curricular, de acordo com o segmento, aulas de Orientação de Estudos, Disciplinas Eletivas, Clubes Juvenis, Protagonismo Juvenil, Assembleias, Preparação Acadêmica e Preparação para o Mundo do Trabalho.

Quadro 3 - Matriz curricular ensino fundamental - $1^{\circ}$ ao $5^{\circ}$ Ano - Escola Plena

\begin{tabular}{|c|c|c|c|c|c|c|c|c|}
\hline Bases & \multicolumn{2}{|c|}{$\begin{array}{c}\text { Área do } \\
\text { Conhecimento }\end{array}$} & $\begin{array}{c}\text { Componentes } \\
\text { Curriculares }\end{array}$ & $1^{\circ}$ Ano & $2^{\circ}$ Ano & $3^{\circ}$ Ano & $4^{\circ}$ Ano & $5^{\circ}$ Ano \\
\hline \multirow{8}{*}{$\begin{array}{c}\text { Base } \\
\text { Nacional } \\
\text { Comum } \\
\text { Curricular }\end{array}$} & \multirow{3}{*}{\multicolumn{2}{|c|}{ Linguagens }} & $\begin{array}{c}\text { Língua } \\
\text { Portuguesa }\end{array}$ & $5 \mathrm{~h}$ & $5 \mathrm{~h}$ & $5 \mathrm{~h}$ & $5 \mathrm{~h}$ & $5 \mathrm{~h}$ \\
\hline & & & Arte & $1 \mathrm{~h}$ & $1 \mathrm{~h}$ & $1 \mathrm{~h}$ & $1 \mathrm{~h}$ & $1 \mathrm{~h}$ \\
\hline & & & $\begin{array}{l}\text { Educação } \\
\text { Física }\end{array}$ & $2 \mathrm{~h}$ & $2 \mathrm{~h}$ & $2 \mathrm{~h}$ & $2 \mathrm{~h}$ & $2 \mathrm{~h}$ \\
\hline & \multicolumn{2}{|c|}{ Matemática } & Matemática & $5 \mathrm{~h}$ & $5 \mathrm{~h}$ & $5 \mathrm{~h}$ & $5 \mathrm{~h}$ & $5 \mathrm{~h}$ \\
\hline & \multicolumn{2}{|c|}{$\begin{array}{c}\text { Ciências da } \\
\text { natureza }\end{array}$} & Ciências & $2 \mathrm{~h}$ & $2 \mathrm{~h}$ & $2 \mathrm{~h}$ & $2 \mathrm{~h}$ & $2 \mathrm{~h}$ \\
\hline & \multirow{3}{*}{\multicolumn{2}{|c|}{$\begin{array}{l}\text { Ciências } \\
\text { humanas }\end{array}$}} & História & $2 \mathrm{~h}$ & $2 \mathrm{~h}$ & $2 \mathrm{~h}$ & $2 \mathrm{~h}$ & $2 \mathrm{~h}$ \\
\hline & & & Geografia & $2 \mathrm{~h}$ & $2 \mathrm{~h}$ & $2 \mathrm{~h}$ & $2 \mathrm{~h}$ & $2 \mathrm{~h}$ \\
\hline & & & $\begin{array}{c}\text { Ensino } \\
\text { Religioso }\end{array}$ & $1 \mathrm{~h}$ & $1 \mathrm{~h}$ & $1 \mathrm{~h}$ & $1 \mathrm{~h}$ & $1 \mathrm{~h}$ \\
\hline \multicolumn{4}{|c|}{ Total de Horas } & $20 \mathrm{~h}$ & $20 \mathrm{~h}$ & $20 \mathrm{~h}$ & $20 \mathrm{~h}$ & $20 \mathrm{~h}$ \\
\hline \multicolumn{2}{|c|}{ Bases } & \multicolumn{2}{|c|}{$\begin{array}{c}\text { Componentes } \\
\text { Curriculares }\end{array}$} & $1^{\circ}$ Ano & $2^{\circ}$ Ano & $3^{\circ}$ Ano & $4^{\circ}$ Ano & $5^{\circ}$ Ano \\
\hline \multirow{7}{*}{\multicolumn{2}{|c|}{ Base Diversificada }} & \multicolumn{2}{|c|}{ Disciplinas Eletivas } & $2 \mathrm{~h}$ & $2 \mathrm{~h}$ & $2 \mathrm{~h}$ & $2 \mathrm{~h}$ & $2 \mathrm{~h}$ \\
\hline & & \multicolumn{2}{|c|}{ Iniciação Cientifica } & $1 \mathrm{~h}$ & $1 \mathrm{~h}$ & $1 \mathrm{~h}$ & $1 \mathrm{~h}$ & $1 \mathrm{~h}$ \\
\hline & & \multicolumn{2}{|c|}{$\begin{array}{c}\text { Protagonismo } \\
\text { Estudantil }\end{array}$} & $1 \mathrm{~h}$ & $1 \mathrm{~h}$ & $1 \mathrm{~h}$ & $1 \mathrm{~h}$ & $1 \mathrm{~h}$ \\
\hline & & \multicolumn{2}{|c|}{ Prática Esportiva } & $3 \mathrm{~h}$ & $3 \mathrm{~h}$ & $3 \mathrm{~h}$ & $3 \mathrm{~h}$ & $3 \mathrm{~h}$ \\
\hline & & \multicolumn{2}{|c|}{$\begin{array}{c}\text { Projeto Educativo } \\
\text { Cultural }\end{array}$} & $3 \mathrm{~h}$ & $3 \mathrm{~h}$ & $3 \mathrm{~h}$ & $3 \mathrm{~h}$ & $3 \mathrm{~h}$ \\
\hline & & \multicolumn{2}{|c|}{$\begin{array}{l}\text { Estudo Aplicado de } \\
\text { Língua Portuguesa }\end{array}$} & $3 \mathrm{~h}$ & $3 \mathrm{~h}$ & $3 \mathrm{~h}$ & $3 \mathrm{~h}$ & $3 \mathrm{~h}$ \\
\hline & & \multicolumn{2}{|c|}{$\begin{array}{l}\text { Estudo Aplicado de } \\
\text { Matemática }\end{array}$} & $3 \mathrm{~h}$ & $3 \mathrm{~h}$ & $3 \mathrm{~h}$ & $3 \mathrm{~h}$ & $3 \mathrm{~h}$ \\
\hline \multicolumn{4}{|c|}{ Total de Horas } & 16 & 16 & 16 & 16 & 16 \\
\hline
\end{tabular}

Fonte: Mato Grosso (2018). 
Quadro 4 - Matriz curricular ensino fundamental - $6^{\circ}$ ao $9^{\circ}$ Ano - Escola Plena

\begin{tabular}{|c|c|c|c|c|c|c|c|}
\hline Bases & \multicolumn{2}{|c|}{$\begin{array}{l}\text { Área do } \\
\text { Conhecimento }\end{array}$} & $\begin{array}{l}\text { Componentes } \\
\text { Curriculares }\end{array}$ & $6^{\circ}$ Ano & $7^{\circ}$ Ano & $8^{\circ}$ Ano & $9^{\circ}$ Ano \\
\hline \multirow{9}{*}{$\begin{array}{c}\text { Base } \\
\text { Nacional } \\
\text { Comum } \\
\text { Curricular }\end{array}$} & \multirow{4}{*}{\multicolumn{2}{|c|}{ Linguagens }} & Língua Portuguesa & $5 \mathrm{~h}$ & $5 \mathrm{~h}$ & $5 \mathrm{~h}$ & $5 \mathrm{~h}$ \\
\hline & & & Arte & $1 \mathrm{~h}$ & $1 \mathrm{~h}$ & $1 \mathrm{~h}$ & $1 \mathrm{~h}$ \\
\hline & & & Educação Física & $2 \mathrm{~h}$ & $2 \mathrm{~h}$ & $2 \mathrm{~h}$ & $2 \mathrm{~h}$ \\
\hline & & & Língua Inglesa & $2 \mathrm{~h}$ & $2 \mathrm{~h}$ & $2 \mathrm{~h}$ & $2 \mathrm{~h}$ \\
\hline & \multicolumn{2}{|c|}{ Matemática } & Matemática & $5 \mathrm{~h}$ & $5 \mathrm{~h}$ & $5 \mathrm{~h}$ & $5 \mathrm{~h}$ \\
\hline & \multicolumn{2}{|c|}{$\begin{array}{l}\text { Ciências da } \\
\text { natureza }\end{array}$} & Ciências & $3 \mathrm{~h}$ & $3 \mathrm{~h}$ & $3 \mathrm{~h}$ & $3 \mathrm{~h}$ \\
\hline & \multirow{3}{*}{\multicolumn{2}{|c|}{$\begin{array}{l}\text { Ciências } \\
\text { humanas }\end{array}$}} & História & $3 \mathrm{~h}$ & $3 \mathrm{~h}$ & $3 \mathrm{~h}$ & $3 \mathrm{~h}$ \\
\hline & & & Geografia & $3 \mathrm{~h}$ & $3 \mathrm{~h}$ & $3 \mathrm{~h}$ & $3 \mathrm{~h}$ \\
\hline & & & Ensino Religioso & $1 \mathrm{~h}$ & $1 \mathrm{~h}$ & $1 \mathrm{~h}$ & $1 \mathrm{~h}$ \\
\hline \multicolumn{4}{|c|}{ Total de Horas } & $25 \mathrm{~h}$ & $25 \mathrm{~h}$ & $25 \mathrm{~h}$ & $25 \mathrm{~h}$ \\
\hline \multicolumn{2}{|c|}{ Bases } & \multicolumn{2}{|c|}{ Componentes Curriculares } & $6^{\circ}$ Ano & $7^{\circ}$ Ano & $8^{\circ}$ Ano & $9^{\circ}$ Ano \\
\hline \multirow{8}{*}{ Base Dive } & & \multicolumn{2}{|c|}{ Disciplinas Eletivas } & $2 \mathrm{~h}$ & $2 \mathrm{~h}$ & $2 \mathrm{~h}$ & $2 \mathrm{~h}$ \\
\hline & & \multicolumn{2}{|c|}{ Iniciação Cientifica } & $1 \mathrm{~h}$ & $1 \mathrm{~h}$ & $1 \mathrm{~h}$ & $1 \mathrm{~h}$ \\
\hline & & \multicolumn{2}{|c|}{ Avaliação Semanal } & $1 \mathrm{~h}$ & $1 \mathrm{~h}$ & $1 \mathrm{~h}$ & $1 \mathrm{~h}$ \\
\hline & sificada & \multicolumn{2}{|c|}{ Protagonismo Estudantil } & $1 \mathrm{~h}$ & $1 \mathrm{~h}$ & $1 \mathrm{~h}$ & $1 \mathrm{~h}$ \\
\hline & & \multicolumn{2}{|c|}{ Prática Esportiva } & $2 \mathrm{~h}$ & $2 \mathrm{~h}$ & $2 \mathrm{~h}$ & $2 \mathrm{~h}$ \\
\hline & & \multicolumn{2}{|c|}{ Projeto Educativo Cultural } & $2 \mathrm{~h}$ & $2 \mathrm{~h}$ & $2 \mathrm{~h}$ & $2 \mathrm{~h}$ \\
\hline & & \multicolumn{2}{|c|}{$\begin{array}{l}\text { Estudo Aplicado de } \\
\text { Língua Portuguesa }\end{array}$} & $2 \mathrm{~h}$ & $2 \mathrm{~h}$ & $2 \mathrm{~h}$ & $2 \mathrm{~h}$ \\
\hline & & \multicolumn{2}{|c|}{$\begin{array}{l}\text { Estudo Aplicado de } \\
\text { Matemática }\end{array}$} & $2 \mathrm{~h}$ & $2 \mathrm{~h}$ & $2 \mathrm{~h}$ & $2 \mathrm{~h}$ \\
\hline \multicolumn{4}{|c|}{ Total de Horas } & 13 & 13 & 13 & 13 \\
\hline
\end{tabular}

Fonte: Mato Grosso (2018).

\section{Considerações finais}

Com uma trajetória de quase uma década, vivenciado por um início conturbado no desdobramento de suas funções, a Escola Estadual Daury Riva chega em 2019 com uma proposta inovadora para a cidade de Juara, a Educação Plena. Dentro desta concepção de Escola Plena e de forma bastante ampla e contemplativa em seu Projeto Político Pedagógico e Regimento Escolar, a instituição oferece uma educação de qualidade, considerando o aluno 
como ser único dotado de desejos e anseios frente a uma vasta gama de possibilidades. Possibilitando ao educando uma trajetória múltipla no decorrer da caminhada escolar, trabalhando de forma interdisciplinar todo o conteúdo da base curricular e da base diversificada, uma junção de múltiplas vertentes que comtemplam a formação integral do ser.

Com uma proposta de mudanças e inovações a Escola Estadual Daury Riva tem como objetivo formar alunos em sua totalidade, com uma proposta de Educação Plena e não é só no sentido técnico da palavra. A promoção de novas e ousadas formas de ensinar, aprendendo e construindo o conhecimento nas mais variadas temporalidades, pois todo aluno interage construindo e sendo construído - de forma física, emocional, psicológica, social, histórico e cultural com outros alunos e da mesma forma ocorre essa interação com o corpo docente.

Entendemos ser de suma importância à busca por novas formas de inovar, principalmente no campo educacional, e é dentro deste contexto que a Escola Estadual Daury Riva vem se reinventado em seu curto tempo de existência. Consideramos ainda a importância da manutenção do presente plano educacional -Escola Plena - por um tempo significativo, pois as mudanças educacionais não surtem efeito imediato de um ano para outro.

\section{REFERÊNCIAS}

BRASIL/MEC. Lei no. 9.394, de 20 de dezembro de 1996. Lei de Diretrizes e Bases da Educação Nacional. Brasília, DF: 20 de dezembro de 1996. Disponível em: https://www2.senado.leg.br/bdsf/bitstream/handle/id/70320/65.pdf. Acesso em: 23 de setembro de 2019.

BRASIL. Secretaria de Educação Fundamental. Parâmetros curriculares nacionais: introdução aos parâmetros curriculares nacionais / Secretaria de Educação Fundamental. - Brasília: MEC/SEF, 1997. 126p. Disponível em:

http://portal.mec.gov.br/seb/arquivos/pdf/livro01.pdf. Acesso em 23 de setembro de 2019.

BRASIL. Ministério da Educação. Manual Operacional de Educação Integral. Brasília, DF. 2014. Disponível em:

http://portal.mec.gov.br/index.php?option=com_docman\&view=download\&alias=15842manual-operacional-de-educacao-integral-2014\&category_slug=junho-2014pdf\&Itemid=30192. Acesso em: 28/03/2019.

BRASIL. Instituto Nacional de Estudos e Pesquisas Educacionais Anísio Teixeira. Plano Nacional de Educação PNE 2014-2024: Linha de Base. - Brasília, DF: Inep, 2015. 404 p. Disponível em: http://portal.inep.gov.br/documents/186968/485745/Plano+Nacional+de+Educa\%C3\%A7\%C 3\%A3o+PNE+2014-2024++Linha+de+Base/c2dd0faa-7227-40ee-a52012c6fc77700f?version=1.1. Acesso em: 25 de março de 2019. 
BRASIL. Constituição da República Federativa do Brasil de 1988 (1998). Brasília. Disponível em: http://www.planalto.gov.br/ccivil_03/constituicao/constituicaocompilado.htm. Acesso em: 09 de outubro de 2019.

FODRA, Sandra Maria. O projeto de vida: escolas do programa ensino integral. 41st. Association for Moral Education Conference - 2015. Disponível em: http://www.fecilcam.br/revista/index.php/anaisame/article/view/1348/835. Acesso em: $10 \mathrm{de}$ outubro de 2019.

GONÇALVES, Antônio Sérgio. Reflexões sobre educação integral e escola de tempo integral. Cadernos Cenpec, volume n ${ }^{\circ}$ 2, p.1-10, $2^{\circ}$ semestre 2006.

HORA, Dayse Martins; COELHO, Lígia Martha Coimbra da Costa. Diversificação curricular e Educação Integral. 2004, p. 1-18. Disponível em:

http://www.unirio.br/cch/neephi/arquivos/divercurriceducint.doc. Acesso em: 10 de outubro de 2019.

MATO GROSSO (Estado). Secretaria de Estado de Educação. Orientações Curriculares: Diversidades Educacionais./ Secretaria de Estado de Educação de Mato Grosso. Cuiabá: Defanti, 2010. 308p. Disponível em: http://www2.seduc.mt.gov.br/documents/9418783/9589638/LIVRO+ORIENTACOES+CUR RICULARES+DAS+DIVERSIDADES+EDUCACIONAIS+com+ficha+catalograficat6SXF86A.pdf/08fde3af-308c-5105-712c-f14918b65a8e. Acesso em 23 de setembro de 2019.

MATO GROSSO (Estado), Secretaria de Estado de Educação. Plano Estadual de Educação. Cuiabá - SEDUC/MT - 2014. Disponível em: http://fne.mec.gov.br/images/PEE/MTPEE.pdf. Acesso em: 25 de março de 2019.

MATO GROSSO (Estado), Diário Oficial do Estado de Mato Grosso. Portaria $\mathbf{N}^{\mathbf{0}}$ 602/2018/GS/SEDUC/MT. Cuiabá - D.O. - 2018. Disponível em: http://cos.seduc.mt.gov.br/upload/permanente/Arquivo/Portaria\%20n\%C2\%BA\%20602\%20 \%20Educacao\%20em\%20tempo\%20integral\%20\%20Escola\%20Plena46708424081133.pdf. Acesso em: 29 de março de 2019.

MATO GROSSO (Estado), Diário Oficial do Estado de Mato Grosso. Portaria $\mathbf{N}^{\mathbf{0}}$ 035/2016/GS?SEDUC/MT. Cuiabá - D.O. - 2018. Disponível em: http://cos.seduc.mt.gov.br/upload/permanente/Arquivo/D.0.\%2026.01.16\%20Port.\%20035\% 202016\%20\%20Procedimentos\%20do\%20processo\%20de\%20impla.\%20de\%20educa\%C3\% A7ao\%20em\%20tempo\%20integra196818097631.pdf. Acesso em: 29 de março de 2019.

MATO GROSSO (Estado). Secretaria de Estado de Educação. Projeto Pedagógico de Educação em Tempo Integral - Escola Plena. Cuiabá - SEDUC/MT - 2019.

PPP. Projeto Político Pedagógico da Escola Estadual Daury Riva - Juara - Mato Grosso. 2015.

PPP. Projeto Político Pedagógico da Escola Estadual Daury Riva - Juara - Mato Grosso. 2018. 
SILVA, Jamerson Antônio de Almeida da; SILVA, Katharine Ninive Pinto. A hegemonia às avessas no Programa Mais Educação. Revista brasileira de Estudos pedagógicos. (online), Brasília, v. 94, n. 238, p. 701-720, set./dez. 2013. Disponível em:

http://www.scielo.br/pdf/rbeped/v94n238/a04v94n238.pdf. Acesso em: 09 de outubro de 2019.

Recebido em: 05 de julho de 2019.

Aprovado em: 05 de novembro de 2019. 